Article

\title{
Salmonella Bacteriophage Diversity According to Most Prevalent Salmonella Serovars in Layer and Broiler Poultry Farms from Eastern Spain
}

\author{
Sandra Sevilla-Navarro ${ }^{1,2}$, Pablo Catalá-Gregori ${ }^{1,2, * \mathbb{C}}$ and Clara Marin ${ }^{2}$ \\ 1 Centro de Calidad Avícola y Alimentación Animal de la Comunidad Valenciana (CECAV), Calle Nules 16, \\ 12539 Castellón, Spain; s.sevilla@cecav.org \\ 2 Departamento de Producción y Sanidad Animal, Salud Pública Veterinaria y Ciencia y Tecnología de los \\ Alimentos, Instituto de Ciencias Biomédicas, Facultad de Veterinaria, Universidad Cardenal Herrera-CEU, \\ CEU Universities, Avenida Seminario s/n, 46113 Moncada, Spain; clara.marin@uchceu.es \\ * Correspondence: p.catala@cecav.org
}

Received: 27 July 2020; Accepted: 18 August 2020; Published: 19 August 2020

check for updates

Simple Summary: There is a lack of knowledge about the impact that phages present in the environment may have against certain Salmonella serovars. Thus, an improved understanding of Salmonella phage diversity will provide a better insight into the role of phages in Salmonella ecology and diversity. The results of this study showed that the poultry farm environment could represent a valuable source of Salmonella phages, which are more varied in broiler than in layer farms.

\begin{abstract}
The exploration of novel nonantibiotic interventions in the field, such as the use of bacteriophages, is necessary to avoid the presence of Salmonella. Bacteriophages are a group of viruses widely distributed in nature, strictly associated with the prokaryotic cell. Researchers have demonstrated the success of phage therapy in reducing Salmonella counts in poultry products. However, the impact that phage concentration in the environment may have against certain Salmonella serovars is not well understood. Therefore, the aim of this study was to assess Salmonella phage prevalence in commercial poultry farms in terms of the production type: layers or broilers. The most prevalent Salmonella serovars isolated in poultry production were used for phage isolation. Salmonella specific phages were isolated from 141 layer and broiler farms located in the Valencia region during 2019. Analysis of the samples revealed that $100 \%$ presented Salmonella phages, the most prevalent being against serovar S. Enteritidis (93\%), followed by S. Virchow (59\%), S. Typhimurium (55\%), S. Infantis $(52 \%)$ and S. Ohio (51\%). These results indicate that poultry farms could represent an important source of Salmonella phages. Nevertheless, further studies are needed to assess the epidemiology of phages against other serovars present in other countries and their diversity from the point of view of molecular studies.
\end{abstract}

Keywords: Salmonella; bacteriophages; prevalence; broilers; layers

\section{Introduction}

Salmonella spp. remain one of the main bacteria involved in food-borne outbreaks and are a major public health hazard worldwide [1]. It is estimated that nontyphoidal Salmonella worldwide cause around 94 million cases of illness and 155,000 deaths per year [2]. The latest data published by the European Food Safety Authority (EFSA) reported 91,857 human cases, 43.2\% of which included hospitalization [3].

There are numerous sources of human salmonellosis infection, but eggs and poultry meat are reported to be the most common sources [3]. The latest data recorded in 2019 showed that $4 \%$ of tested 
flocks were positive for Salmonella detection, from which $1.1 \%$ were $S$. Enteritidis and $S$. Typhimurium target serovars [3]. However, among those outside the target serovars, the most common reported was $S$. Infantis. Considering the production chain for meat and meat products, the highest percentages of positive samples were found for fresh broilers meat, with $S$. Enteritidis, $S$. Typhimurium, and the S.a monophasic Typhimurium variant [3] as the main serovars involved in human outbreaks. In this line, the introduction of National Salmonella Control Programmes (NSCP) to control the bacterium at the field level resulted in an important reduction in the prevalence of poultry Salmonella serovars in Europe [4]. However, total elimination of the bacterium from poultry flocks is still difficult, and new cases of salmonellosis emerge every year, resulting in economically significant losses for the poultry sector [3].

In addition, the emergence of several Salmonella serovars resistant to multiple antibiotics in poultry-derived products underscores a significant food safety and poultry production hazard [5]. For this reason, the exploration of novel nonantibiotic interventions in the field should be studied to avoid the presence of antibiotic-resistant strains [5].

Bacteriophages or phages are a group of viruses widely distributed in nature, whose life cycle is strictly associated with the prokaryotic cell [6,7]. The use of host-specific phages has been promoted as a cost-effective and adaptable approach to control zoonotic bacteria [8-11]. Moreover, phages seem to be a good alternative due to their self-perpetuating, self-limiting and specificity characteristics [12]. Researchers have demonstrated the success of phage therapy in poultry products, reducing Salmonella counts from broiler carcasses after phage administration. Higgins et al. (2005) reduced Salmonella counts in $100 \%$ of broiler carcasses where phages were inoculated [13]. Moreover, Kang et al. (2013) decreased Salmonella counts on chicken skin by up to 3 logs after the application of a single phage [14]. Other research showed Salmonella decreasing counts by 1 log on fresh egg shells after application of the phage [7].

However, the impact that phages present in the environment may have against certain Salmonella serovars with relevance in food safety is not well understood. Thus, an improved understanding of Salmonella phage diversity may provide better insights into the role of phages in Salmonella ecology and diversity and facilitate an improved approach toward biocontrol and diagnostics [15,16].

The aim of this study was, therefore, to assess Salmonella phage diversity in commercial layer and broiler poultry farms in relation to the most prevalent serovars in the poultry production system in Eastern Spain. Thus, in this study we tested whether occurrence of phages against Salmonella was related to the poultry production type.

\section{Materials and Methods}

\subsection{Salmonella Strain Selection for Phage Isolation}

Salmonella strains used for phage detection were field strains selected from the strain collection repository from the Centro de Calidad Avícola y Alimentación Animal de la Comunidad Valenciana (CECAV), which is the benchmark laboratory for Salmonella field strains isolation from poultry farms throughout Spain. The origin of the field strains was the NSCP [4], and each selected strain used in this study was isolated from poultry farms. All selected serovars were those most prevalent in poultry production in Spain [3]: S. Enteritidis, S. Typhimurium, S. Typhimurium monophasic variant, S. Kentucky, S. Hadar, $S$. Senftenberg, S. Ohio, $S$. Infantis and $S$. Virchow. The strains were thawed and revived on nutrient agar (Oxoid Ltd., England, UK) and incubated at $37.5 \pm 2{ }^{\circ} \mathrm{C}$ for $18 \pm 4 \mathrm{~h}$. For characterization of the strains, the antimicrobial susceptibility pattern was performed. To this end, Salmonella sensititre plates (Gram Negative MIC Plate) were used to assess antimicrobial susceptibility of isolated strains. A $10 \mu \mathrm{L}$ aliquot of the inoculum was aseptically transferred to $10 \mathrm{~mL}$ sensititre cation-adjusted Mueller-Hinton broth, and plaques were inoculated according to manufacturer instructions. Plates were read at $18 \mathrm{~h}$ to $24 \mathrm{~h}$ manually by visualization of a growth button on the bottom of the microtitre well using a light box. Reading the results was performed according to the manufacturer's instructions. 
The antibiotics selected were those set forth in Decision 2013/653 [17], including: 2 quinolones: ciprofloxacin (CIP, 0.015-8 $\mu \mathrm{g} / \mathrm{mL}$ ) and nalidixic Acid (NAL, 4-128 $\mu \mathrm{g} / \mathrm{mL}$ ); 2 B-lactams: meropenem (MERO, 0.03-16 $\mu \mathrm{g} / \mathrm{mL}$ ) and ampicillin (AMP, 1-64 $\mu \mathrm{g} / \mathrm{mL}$ ), one phenicol: chloramphenicol (C, 8-128 $\mu \mathrm{g} / \mathrm{mL}$ ); one pyrimidine: trimethoprim (TM, $\mu \mathrm{g} / \mathrm{mL}$ ); one tetracycline: tetracycline (TET, $\mu \mathrm{g} / \mathrm{mL})$; one macrolide: azithromycin (AZM, 2-64 $\mu \mathrm{g} / \mathrm{mL}$ ); one glycylcycline: tigecycline (TGC, $0.25-8 \mu \mathrm{g} / \mathrm{mL}$ ); 2 cephalosporin: ceftazidime (CAZ, $0.5-8 \mu \mathrm{g} / \mathrm{mL}$ ) and cefotaxime (CTX, $0.25-4 \mu \mathrm{g} / \mathrm{mL}$ ); one polymyxin: colistin (COL, 1-16 $\mu \mathrm{g} / \mathrm{mL}$ ); one potentiated sulfonamide: sulfamethoxazole (SMX, 8-1024 $\mu \mathrm{g} / \mathrm{mL}$ ), and one aminoglycoside: gentamicin (GN, $0.5-32 \mu \mathrm{g} / \mathrm{mL}$ ). Multidrug resistance (MDR) was defined as acquired resistance to at least one agent in three or more antimicrobial classes [18].

\subsection{Study Sample}

A total of 141 poultry farms located in the Eastern Spain were sampled: 108 layer farms (from 41 to 64 weeks of rearing) and 33 broiler farms (ranging from 35 to 42 days of rearing), all of them belonging to three of the main companies in Spain that handle the majority of the broilers and layers reared in Spain (one company from broiler and two companies from laying hens). Farms selected for the study were conventional commercial poultry farms of broilers and layers. All flocks of laying hens analyzed (lines Lohmann and Hyline) were vaccinated against Salmonella according to the standard vaccination guidelines. To this end, Salmonella vaccination was performed with the vaccine Salmovac 440, a live vaccine given orally in a triple dose through water (day 1, week 6 and week 15) to protect against $S$. Enteritidis and $S$. Typhimurium serovars according to mandatory regulations in the Valencia region [19]. Moreover, layers were reared in cages with a density of $750 \mathrm{~cm}^{2} /$ hen. With respect to broiler production, all analyzed flocks (lines Cobb and Ross) were reared on the floor in cages containing wood shavings to a depth around $10 \mathrm{~cm}$, and with a density of $33 \mathrm{~kg} / \mathrm{m}^{2}$. All the animals were kept indoors under controlled conditions equipped with programmable electrical lights, automated electric heating and forced ventilation [20].

\subsection{Faeces Samples Collection}

From each farm, two faeces samples of $150 \mathrm{~g}$ were taken from different points of the facility [4]. Once in the laboratory, faeces samples collected from each farm were pooled and placed in sterile pots: $25 \mathrm{~g}$ to assess Salmonella status of the farm and $10 \mathrm{~g}$ for phage detection (as described below).

\subsection{Salmonella Isolation}

Samples were analyzed according to the ISO 6579-1:2017 [21]. Firstly, faeces samples were pre-enriched 1:10 $(v / v)$ in buffered peptone water 2.5\% (BPW, Scharlau ${ }^{\circledR}$, Barcelona, Spain) and incubated at $37 \pm 1{ }^{\circ} \mathrm{C}$ for $18 \pm 2 \mathrm{~h}$. After incubation, the pre-enriched samples were transferred onto a Semi-Solid Modification Rappaport Vassiliadis agar plate (MSRV, Difco ${ }^{\circledR}$, Valencia, Spain), and incubated at $41.5 \pm 1{ }^{\circ} \mathrm{C}$ for $24-48 \mathrm{~h}$. The resulting culture was used to streak xylose-lysine-deoxycholate (XLD, Liofilchem, Valencia, Spain) and ASAP (ASAP chromogenic media, bioMérieux, Madrid, Spain) agar plates, and incubated at $37 \pm 1^{\circ} \mathrm{C}$ for $24 \mathrm{~h}$. Next, five typical colonies were streaked onto predried nutrient agar plates (Scharlab ${ }^{\circledR}$, Barcelona, Spain) at $37 \pm 1{ }^{\circ} \mathrm{C}$ for $24 \pm 3 \mathrm{~h}$ and confirmed as Salmonella spp. using the API (API-20 ${ }^{\circledR}$, bioMérieux, Madrid, Spain) biochemical test.

\subsection{Salmonella Phage Isolation}

Phages were isolated from faeces collected by an enrichment procedure [22]. To do so, $10 \mathrm{~g}$ of each faeces sample were diluted in $90 \mathrm{~mL}$ of Luria Bertani (LB) (VWR Chemicals, Barcelona, Spain) and incubated along with each selected Salmonella serovar overnight at $37^{\circ} \mathrm{C}$. After incubation, $2 \mathrm{~mL}$ of this enrichment culture was centrifuged $16,000 \times g$ for $5 \mathrm{~min}$. The supernatant was then filtered through a $0.22 \mu \mathrm{m}$ membrane.

Phages were isolated and purified in a spot test by the double agar method. Briefly, bacterial suspensions of each serovar were adjusted to an optical density at $600 \mathrm{~nm}(\mathrm{OD}=600)$ of 0.2 
$\left(\sim 10^{8} \mathrm{CFU} / \mathrm{mL}\right)$ in $\mathrm{LB}$ and incubated at $37^{\circ} \mathrm{C}$ for $4 \mathrm{~h}$. Then, $200 \mu \mathrm{L}$ of cultures were added to $5 \mathrm{~mL}$ of LB agar (LB with $0.6 \%$ agar) tempered to $45^{\circ} \mathrm{C}$ and poured onto previously prepared and dried LB basal agar (with $1.6 \%$ agar). Then, $10 \mathrm{uL}$ of each filtrate were spotted onto the surfaces of Salmonella lawns and incubated overnight at $37^{\circ} \mathrm{C}$. After the incubation, morphologically different plaques were selected and resuspended in $1 \mathrm{~mL}$ of PBS. Ten-fold serial dilutions of the phage suspension were plated by the double agar layer method, and phages that produced clear plaques were selected. This procedure was repeated three times to obtain a single type of phage [23].

\subsection{Statistical Analysis}

We tested whether occurrence of phages against Salmonella was related to the poultry production system. To do so, we fitted a generalized linear model (GLM) where occurrence of Salmonella phage was the response variable and the sample type (faeces from different broiler and layer farms), Salmonella serovar $(n=9)$, genetic lines $(n=2$, for both poultry production type), poultry companies $(n=1$ and $\mathrm{n}=2$, for broilers and layers, respectively), husbandry $(\mathrm{n}=1)$, Salmonella vaccine strain $(\mathrm{n}=1)$ were the factors.

For this analysis, the error was designated as having a binomial distribution and the probit link function was used. Binomial data for each sample were assigned a 1 if a Salmonella phage was isolated or a 0 if not. A $p$-value $<0.05$ was considered to indicate a statistically significant difference. Differences in binomial traits for variables, genetic lines, poultry companies, husbandry and Salmonella vaccine strain, were not significant and were excluded from the model. Finally, a descriptive analysis of the patterns obtained against different Salmonella serovars per farm, and antimicrobial resistance of the strains, was carried out. Analyses were carried out using a commercially available software program (SPSS 21.0 software package; SPSS Inc., Chicago, IL, USA, 2002).

\section{Results}

In this study, a total of 141 faeces samples were collected from poultry farms. From each, 141 pools of $25 \mathrm{~g}$ were analyzed to assess Salmonella status of the farm, and 1269 analyses were done for specific phages isolation (farm $\times$ serovar) (Figure 1). No Salmonella was detected in any farm, although Salmonella phages were detected in all farms sampled, at least against one of the serovars included in this study.

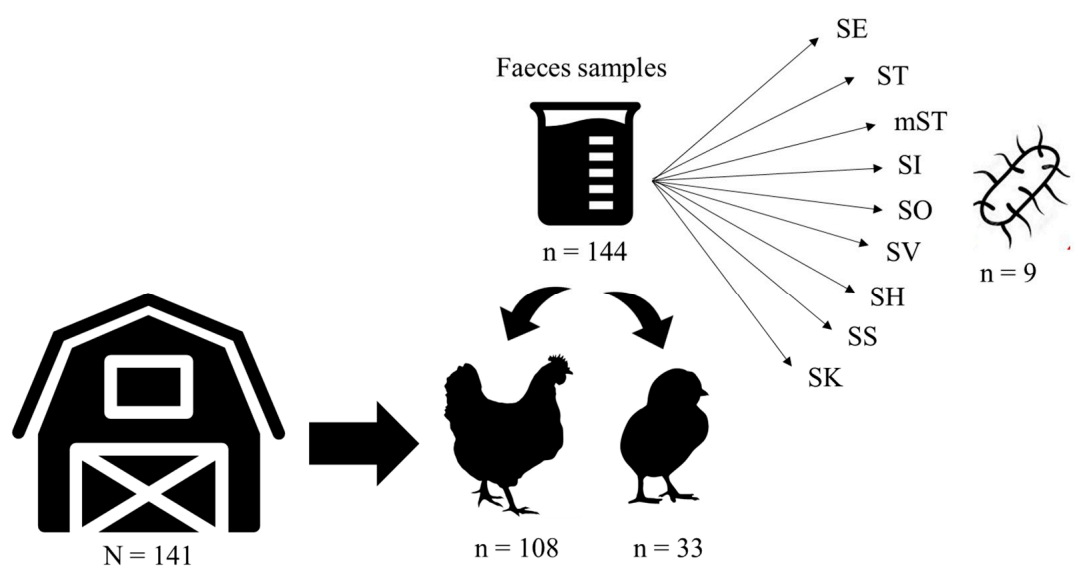

Figure 1. Diagram of the experiment carried out to assess the specific phage isolation in each farm $(n=141)$ per each Salmonella serovar $(n=9)$. SE: S. Enteritidis; ST: S. Typhimurium; mST: S. Typhimurium monophasic variant, SK: S. Kentucky; SH: S. Hadar; SS: S. Senftenberg; SO: S. Ohio; SI: S. Infantis; SV: S. Virchow.

\subsection{Salmonella Antimicrobial Susceptibility Characterization}

From different Salmonella serovars from the poultry sector included in this study $(\mathrm{n}=9), 56 \%$ were resistant to at least one of the fourteen antibiotics tested, and $44 \%$ were MDR to 3 or more of the 
groups of antibiotics tested. Salmonella serovars MDR were S. Typhimurium monophasic variant, $S$. Typhimurium and $S$. Virchow. The highest percentages of antimicrobial resistance (AMR) were found to be TET (44\%) followed by AMP (33\%), NAL (33\%), SMX (22\%) TMP (11\%), and CHL (11\%). Resistance to MERO, AZM, TGC, CAZ, COL, GN and CTX was not observed.

\subsection{Salmonella Phage Prevalence in Poultry Farms}

From 1269 analyses done for specific phages isolation (farm $\times$ serovar), statistically significant differences were found according to poultry production type $(p<0.05)$. Layer and broiler farms presented at least one Salmonella serovar-specific phage in 42\% (408/972) and 53\% (156/297) of faeces samples analyzed, respectively. From farms analyzed, 9.2\% (13/141) of samples presented phages against one serovar, 13.5\% (19/141) against two serovars, 25.5\% (36/141) against three serovars, $19.9 \%$ (28/141) against four serovars, 17\% (24/141) against five serovars, 9.9\% (14/141) against six serovars, $2.1 \%(3 / 141)$ against seven serovars and eight serovars, and $0.7 \%$ (1/141) against all serovars. The lysis spectrum patterns are described in Figure 2.

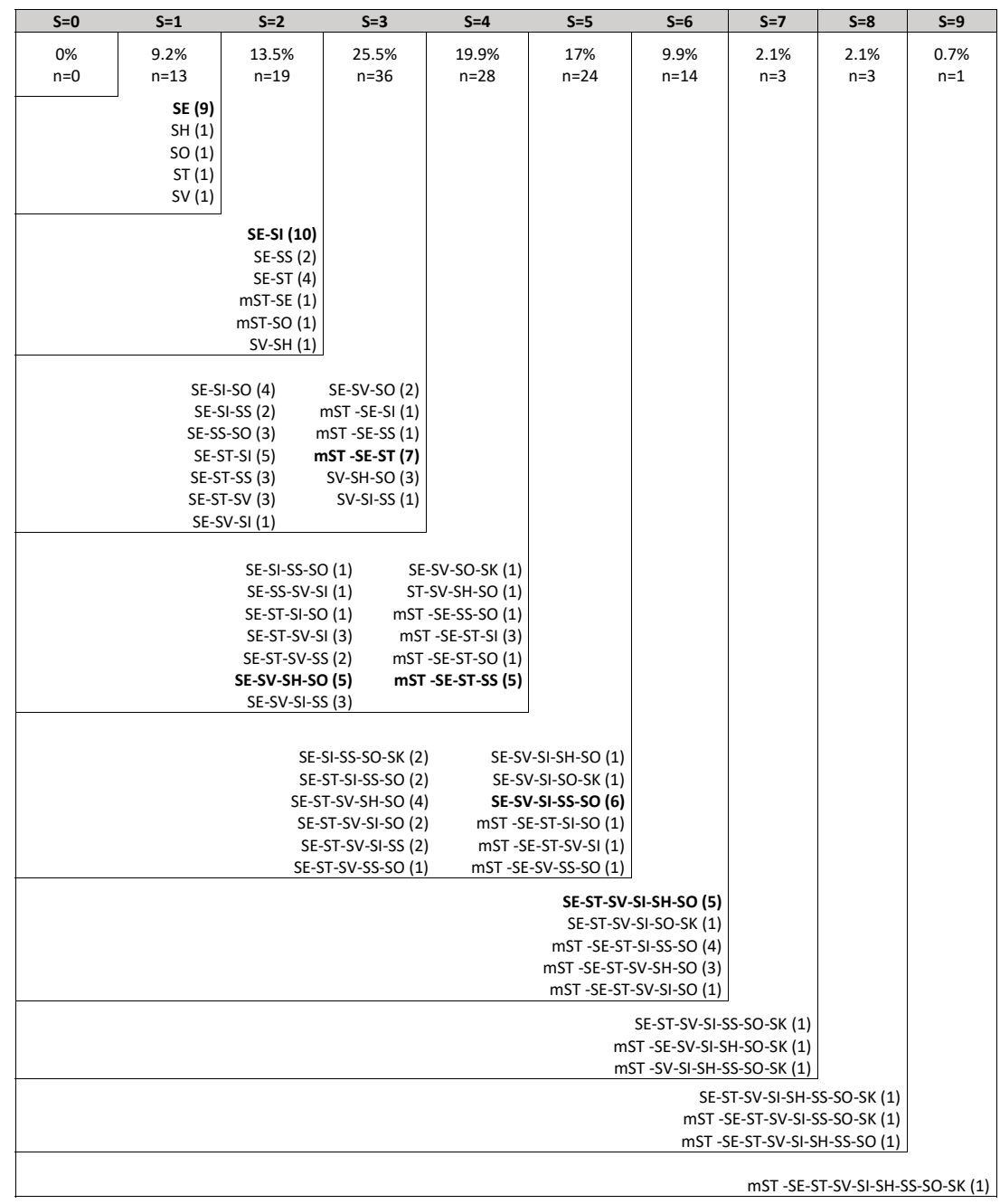

Figure 2. Phage lysis spectrum patterns obtained against different Salmonella serovars per farm. S: number of Salmonella serovars sensitive against phages per farm; n: Number of farms; SE: S. Enteritidis; ST: S. Typhimurium; mST: S. Typhimurium monophasic variant, SK: S. Kentucky; SH: S. Hadar; SS: S. Senftenberg; SO: S. Ohio; SI: S. Infantis; SV: S. Virchow. The number of farms where each phage pattern was obtained is shown within parentheses. Most prevalent patterns are represented in bold letters. 


\subsection{Prevalence of Salmonella Phages per Serovar and Poultry Production Type}

Regardless of the poultry production type (layers or broilers), statistically significant differences were shown among serovar-specific phages isolated $(p<0.05)$. The most prevalent Salmonella phage present was against S. Enteritidis serovar (93\%), followed by S. Virchow (59\%), S. Typhimurium (55\%), S. Infantis (52\%) and S. Ohio (51\%) (Table 1$)$.

Table 1. Percentage of Salmonella phages isolated from poultry farms related to Salmonella serovars included in the study.

\begin{tabular}{cccc}
\hline Strain & $\mathbf{n}$ & $\mathbf{\%}$ & SEM \\
\hline SE & 131 & $93^{\mathrm{g}}$ & 0.022 \\
SV & 83 & $59^{\mathrm{f}}$ & 0.041 \\
ST & 78 & $55^{\mathrm{f}}$ & 0.042 \\
SI & 73 & $52^{\mathrm{f}}$ & 0.042 \\
SO & 72 & $51^{\mathrm{f}}$ & 0.042 \\
SS & 50 & $35^{\mathrm{d}, \mathrm{e}}$ & 0.040 \\
mST & 36 & $26^{\mathrm{c}, \mathrm{d}}$ & 0.037 \\
SH & 29 & $21^{\mathrm{b}}$ & 0.034 \\
SK & 12 & $9^{\mathrm{a}}$ & 0.023 \\
\hline
\end{tabular}

a, b, c, d, e, f, g: Percentage with different superscripts means statistically significant difference within column; SEM: Standard error of the mean; $n$ : Number of positive farms; SE: S. Enteritidis; ST: S. Typhimurium; mST: S. Typhimurium monophasic variant, SK: S. Kentucky; SH: S. Hadar; SS: S. Senftenberg; SO: S. Ohio; SI: S. Infantis; SV: S. Virchow.

With respect to layers, statistically significant differences were shown among Salmonella phages isolated $(p<0.05)$. The highest percentage of phage present was against $S$. Enteritidis $(94 \%)$, followed by $S$. Typhimurium (53\%), S. Infantis (52\%), S. Virchow (47\%) and S. Ohio (44\%). In addition, regarding broiler production, statistically significant differences were shown among Salmonella phages isolated $(p<0.05)$. The highest percentage of phages was against $S$. Virchow $(97 \%)$ and $S$. Enteritidis $(91 \%)$, followed by $S$. Ohio $(76 \%)$ and $S$. Typhimurium $(64 \%)$. However, none of the broiler samples collected presented phages against $S$. Kentucky serovar (Table 2).

Table 2. Percentage of Salmonella phages isolated per serovar within poultry production type.

\begin{tabular}{|c|c|c|c|c|c|c|}
\hline \multirow[b]{3}{*}{ Strain } & \multicolumn{6}{|c|}{ Poultry Production Type } \\
\hline & \multicolumn{3}{|c|}{ Layers } & \multicolumn{3}{|c|}{ Broilers } \\
\hline & $\mathbf{n}$ & $(\%)$ & SEM & $\mathbf{n}$ & $(\%)$ & SEM \\
\hline SE & 101 & $94^{\mathrm{E}}$ & 0.024 & 30 & $91^{\mathrm{e}, \mathrm{f}}$ & 0.050 \\
\hline ST & 57 & $53^{\mathrm{D}}$ & 0.048 & 21 & $64^{\mathrm{d}, \mathrm{e}}$ & 0.084 \\
\hline $\mathrm{mST}$ & 34 & $31^{\mathrm{B}}$ & 0.045 & 2 & $6^{b}$ & 0.042 \\
\hline SK & 12 & $11^{\mathrm{A}}$ & 0.030 & 0 & $0^{a}$ & 0.000 \\
\hline $\mathrm{SH}$ & 12 & $11^{\mathrm{A}}$ & 0.030 & 17 & $52^{c, d}$ & 0.087 \\
\hline SS & 38 & $35^{\mathrm{B}, \mathrm{C}}$ & 0.046 & 12 & $36^{c}$ & 0.084 \\
\hline $\mathrm{SO}$ & 47 & $44^{\mathrm{C}, \mathrm{D}}$ & 0.048 & 25 & $76^{\mathrm{e}}$ & 0.075 \\
\hline SI & 56 & $52^{\mathrm{D}}$ & 0.048 & 17 & $52^{c, d}$ & 0.087 \\
\hline SV & 51 & $47^{\mathrm{D}}$ & 0.048 & 32 & $97^{\mathrm{f}}$ & 0.030 \\
\hline
\end{tabular}

$\mathrm{a}, \mathrm{b}, \mathrm{c}, \mathrm{d}, \mathrm{e}, \mathrm{f}$ : percentage with different superscripts means statistically significant difference within column; $\mathrm{A}, \mathrm{B}, \mathrm{C}, \mathrm{D}, \mathrm{E}$ : percentage with different superscripts means statistically significant difference within column; SEM: Standard error of the mean; n: number of samples positive for the presence of a phage against Salmonella; SE: S. Enteritidis; ST: $S$. Typhimurium; mST: S. Typhimurium monophasic variant, SK: S. Kentucky; SH: S. Hadar; SS: S. Senftenberg; SO: $S$. Ohio; SI: S. Infantis; SV: S. Virchow.

Moreover, statistically significant differences were shown between different poultry production type and phages isolated. From broiler farms, a higher prevalence of phages was observed against $S$. Virchow, $S$. Ohio and S. Hadar. Conversely, the highest phage prevalence against the monophasic $S$. Typhimurium variant and $S$. Kentucky, was obtained from samples from laying hens $(p<0.05)$. No 
statistically significant differences were found between poultry production type, and phage isolation against $S$. Enteritidis, $S$. Typhimurium, $S$. Infantis and $S$. Senftenberg strains $(p>0.05)$ (Figure 3).

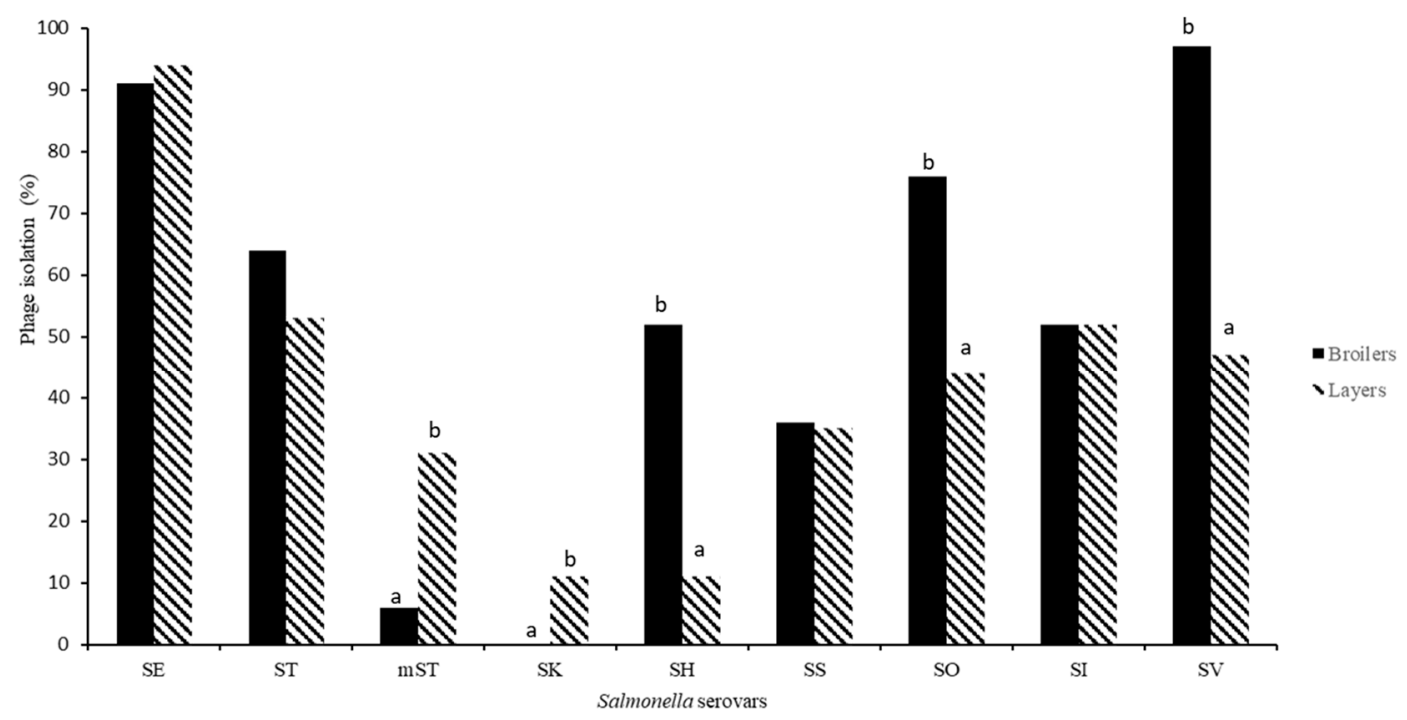

Figure 3. Percentage of Salmonella phages isolated related to serovars and poultry production type (layers vs. broilers). a, b Superscript indicates significant differences in Salmonella phage isolated according to poultry production type. SE: S. Enteritidis; ST: S. Typhimurium; mST: S. Typhimurium monophasic variant, SK: S. Kentucky; SH: S. Hadar; SS: S. Senftenberg; SO: S. Ohio; SI: S. Infantis; SV: S. Virchow.

\section{Discussion}

The diversity of Salmonella phages in poultry farms regarding their production type (broilers or layers) and the most prevalent Salmonella serovars in the Eastern Spain were analyzed in this study. Although Salmonella spp. were not present in any of the farms assessed, phages from several serovars of public health and poultry production importance were present in $100 \%$ of the samples collected. These results showed that although the bacterium is not present in the farm environment, its specific phages can remain in it.

It is claimed that AMR will be the main cause of deaths worldwide by 2050, overtaking other major causes of deaths such as cancer or road traffic accidents [24,25]. For this reason, the reduction of antimicrobial use at the field level throughout Europe is one of the most important aims in the poultry sector [26]. Results of this study showed Salmonella strains with a high percentage of antimicrobial resistance, especially against TET, AMP and NAL, three of the antibiotics most frequently used to treat poultry, and also used against human diseases $[27,28]$. Although Salmonella treatment with antibiotics is banned in the EU, its resistance to antibiotics could be acquired from different sources, such as the environment or antibiotics used to control other infections (E. coli) [29]. Phage patterns obtained against different Salmonella serovars per farm in this study indicated that the environment of animal farms, especially poultry operations, could represent an important source of Salmonella phages against several serovars [30,31]. In this sense, the phages obtained could be effective to combat these antibiotic-resistant strains, with the aim of controlling Salmonella AMR and its spread to the food chain [32].

Regarding Salmonella phages per serovar and poultry production type, S. Enteritidis, $S$. Typhimurium and $S$. Typhimurium monophasic variant phages were three of the phages most frequently isolated in poultry farms. This could be explained by the strict vaccination programs implemented in the poultry production system. Vaccination against $S$. Enteritidis is mandatory in all commercial layer flocks, and optional for layer and broiler breeders [33]. In addition, the vaccination programme is stricter in the Valencia region where, since 2008 , it is mandatory to vaccinate not only 
against $S$. Enteritidis, but also against $S$. Typhimurium [19]. Live vaccination in poultry maintains the Salmonella vaccine strain in birds, as well as the house environment [34-36], and could encourage phage presence in the field. In this context, the latest data recovered from official checks in the Valencia region showed that $100 \%$ of $S$. Enteritidis strains isolated from rearing layers were $S$. Enteritidis vaccine strains (unpublished data). Moreover, specific phages against $S$. Typhimurium monophasic variant have been found, which may be explained by the mandatory oral administration of $S$. Typhimurium vaccine, which could provide cross-immunization against $S$. Typhimurium monophasic variant [37].

A high prevalence of phages against $S$. Ohio, $S$. Infantis and $S$. Virchow have been found in this study; these are three of the main serovars isolated in the Valencia region from the NSCP (unpublished data). These results are in line with other researchers, who stated that the presence of phages in the farm environment would suggest the bacterial strain has been present at some point in the recent past [12,38]. In addition, this fact could be used for the indirect detection of pathogens based on their specificity towards bacteria [32,39]. In this line, phages against $S$. Virchow, $S$. Hadar and $S$. Ohio were observed to be more prevalent in broilers than in layers. These results are in accordance with data recovered from the Salmonella control programme in the Valencia region, as neither S. Virchow nor S. Hadar were isolated from laying farms (unpublished data). Moreover, Marin and Lainez (2009) also demonstrated that the main serovars isolated from broiler farms in the Valencia Region were $S$. Virchow, $S$. Ohio and $S$. Hadar [40]. On the other hand, no statistical differences have been found between the poultry production type and the presence of phages against $S$. Enteritidis, $S$. Typhimurium, $S$. Infantis, and $S$. Senftenberg. This result could be related to the historically close relationship between these serotypes and both layer and broiler production systems [41].

\section{Conclusions}

In conclusion, the results of this study showed that the poultry farm environment could represent a valuable source of Salmonella phages. A wide Salmonella phage diversity was present in the broiler and layer farms analyzed, being more varied in broilers. Nevertheless, further studies are needed to study the epidemiology of phages against other serovars present in other countries and its diversity from the point of view of molecular studies.

Author Contributions: Conceptualization: C.M., and S.S.-N., data curation: S.S.-N., methodology: C.M., S.S.-N. and P.C.-G.; investigation: S.S.-N.; writing-original draft preparation: C.M., and S.S.-N, writing-review and editing: C.M., S.S.-N., and P.C.-G; project administration: P.C.-G.; funding acquisition: P.C.-G. All authors have read and agreed to the published version of the manuscript.

Funding: This research received no external funding.

Acknowledgments: We would like to thank the Centre for Poultry Quality and Animal Feed of the Valencian Community (CECAV) for their financial support and to the veterinarian María Ahis for the technical support. The English text version was revised by N. Macowan English Language Service.

Conflicts of Interest: The authors declare no conflict of interest.

\section{Abbreviations}

The following abbreviations are used in this manuscript:

$\begin{array}{ll}\text { EFSA } & \text { European Food Safety Authority } \\ \text { AMR } & \text { Antimicrobial Resistance } \\ \text { NSCP } & \text { National Salmonella Control Programmes } \\ \text { CIP } & \text { Ciprofloxacin } \\ \text { NAL } & \text { Nalidixic Acid } \\ \text { MERO } & \text { Meropenem } \\ \text { AMP } & \text { Ampicillin } \\ \text { C } & \text { Chloramphenicol } \\ \text { TM } & \text { Trimethoprim } \\ \text { TET } & \text { Tetracycline } \\ \text { AZM } & \text { Azithromycin }\end{array}$




$\begin{array}{ll}\text { TGC } & \text { Tetracycline } \\ \text { CAZ } & \text { Ceftazidime } \\ \text { CTX } & \text { Cefotaxime } \\ \text { COL } & \text { Colistin } \\ \text { SMX } & \text { Sulfamethoxazole } \\ \text { GN } & \text { Gentamicin } \\ \text { MDR } & \text { Multidrug resistance } \\ \text { LB } & \text { Luria-Bertani } \\ \text { OD } & \text { Optical density } \\ \text { GLM } & \text { Generalized Linear Model }\end{array}$

\section{References}

1. WHO (World Health Organization). Salmonella (Non-Typhoidal). Available online: https://www.who.int/ news-room/fact-sheets/detail/salmonella-(non-typhoidal) (accessed on 4 June 2020).

2. Ao, T.T.; Feasey, N.A.; Gordon, M.A.; Keddy, K.H.; Angulo, F.J.; Crump, J.A. Global burden of invasive nontyphoidal Salmonella disease, 2010. Emerg. Infect. Dis. 2015, 21, 941-949. [CrossRef] [PubMed]

3. EFSA and ECDC (European Food Safety Authority and European Centre for Disease Control). The European union one health 2018 zoonoses report. EFSA J. 2019, 17. [CrossRef]

4. NSCP (National Salmonella Control Programes) PNCS. Programa Nacional de Control de Determinados Serotipos de Salmonella en la Especie Gallus Gallus; Fisheries and Food; Spanish Ministery of Agriculture: Madrid, Spain, 2020.

5. Nair, D.V.T.; Venkitanarayanan, K.; Johny, A.K. Antibiotic-resistant Salmonella in the food supply and the potential role of antibiotic alternatives for control. Foods 2018, 7, 167. [CrossRef] [PubMed]

6. Wernicki, A.; Nowaczek, A.; Urban-Chmiel, R. Bacteriophage therapy to combat bacterial infections in poultry. Virol. J. 2017, 14, 179. [CrossRef]

7. Moye, Z.D.; Woolston, J.; Sulakvelidze, A. Bacteriophage applications for food production and processing. Viruses 2018, 10, 205. [CrossRef]

8. Atterbury, R.J.; van Bergen, M.A.P.; Ortiz, F.; Lovell, M.A.; Harris, J.A.; de Boer, A.; Wagenaar, J.A.; Allen, V.M.; Barrow, P.A. Bacteriophage therapy to reduce Salmonella colonization of broiler chickens. Appl. Environ. Microbiol. 2007, 73, 4543-4549. [CrossRef]

9. Borie, C.; Albala, I.; Sànchez, P.; Sánchez, M.L.; Ramírez, S.; Navarro, C.; Morales, M.A.; Retamales, J.; Robeson, J. Bacteriophage treatment reduces Salmonella colonization of infected chickens. Avian Dis. 2008, 52, 64-67. [CrossRef]

10. Ahmadi, M.; Amir Karimi Torshizi, M.; Rahimi, S.; Dennehy, J.J. Prophylactic bacteriophage administration more effective than post-Infection administration in reducing Salmonella enterica serovar Enteritidis shedding in Quail. Front. Microbiol. 2016, 7, 1-10. [CrossRef]

11. Sevilla-Navarro, S.; Marin, C.; Cortés, V.; García, G.; Vega, S.; Catalá-Gregori, P. Autophage as a control measure for Salmonella in laying hens-ScienceDirect. Poult. Sci. 2019, 97, 4367-4373. [CrossRef]

12. Wang, G.; Jin, J.; Asakawa, S.; Kimura, M. Survey of major capsid genes (g23) of T4-type bacteriophages in rice fields in Northeast China. Soil Biol. Biochem. 2009, 41, 423-427. [CrossRef]

13. Higgins, J.P.; Higgins, S.E.; Guenther, K.L.; Huff, W.; Donoghue, A.M.; Donoghue, D.J.; Hargis, B.M. Use of a specific bacteriophage treatment to reduce Salmonella in poultry products. Poult. Sci. 2005, 84, 1141-1145. [CrossRef] [PubMed]

14. Kang, H.W.; Kim, J.W.; Jung, T.S.; Woo, G.J. wksl3, a new biocontrol agent for Salmonella enterica serovars Enteritidis and typhimurium in foods: Characterization, application, sequence analysis, and oral acute toxicity study. Appl. Environ. Microbiol. 2013, 79, 1956-1968. [CrossRef] [PubMed]

15. Wongsuntornpoj, S.; Moreno Switt, A.I.; Bergholz, P.; Wiedmann, M.; Chaturongakul, S. Salmonella phages isolated from dairy farms in Thailand show wider host range than a comparable set of phages isolated from U.S. dairy farms. Vet. Microbiol. 2014, 172, 345-352. [CrossRef] [PubMed] 
16. Crabb, H.K.; Lee Allen, J.; Maree Devlin, J.; Matthew Firestone, S.; Reginald Wilks, C.; Rudkin Gilkerson, J. Salmonella spp. transmission in a vertically integrated poultry operation: Clustering and diversity analysis using phenotyping (serotyping, phage typing) and genotyping (MLVA). PLoS ONE 2018, 13, e0201031. [CrossRef]

17. European Union. 2013/652/EU: Commission Implementing Decision of 12 November on the Monitoring and Reporting of Antimicrobial Resistance in Zoonotic and Commensal Bacteria (Notified Under Document C(2013) 7145); CELEX1; Official Journal of the European Union: Luxembourg, 2013.

18. EFSA and ECDC. EU protocol for harmonised monitoring of antimicrobial resistance in human Salmonella and Campylobacter isolates. Stockholm SC 2016, 3. [CrossRef]

19. Plan Anual Zoosanitario de la Comunidad Valenciana (PAZ). Resolucion 46/2018, 11th of January, por la que se Aprueba el Plan Anual Zoosanitario Para 2009 de la Comunitat Valenciana y Otras Actuaciones Complementarias. In Porceedings of the Diari Oficial de la Comunitat Valenciana. Available online: https://www.dogv.gva.es/datos/2019/01/21/pdf/2019_452.pdf (accessed on 4 June 2020).

20. Spanish Royal Decree (RD) 53/2013, de 1 de febrero, por el que se establecen las normas básicas aplicables para la protección de los animales utilizados en experimentación y otros fines científicos, incluyendo la docencia. Bol. Off. Estado 2013, 34, 11370-11421.

21. ISO 6579-1:2017-Microbiology of the Food Chain-Horizontal Method for the Detection, Enumeration and Serotyping of Salmonella-Part 1: Detection of Salmonella Spp. Available online: https://www.iso.org/standard/ 56712.html (accessed on 4 June 2020).

22. Hyman, P. Phages for phage therapy: Isolation, characterization, and host range breadth. Pharmaceuticals 2019, 12, 35. [CrossRef]

23. Cortés, P.; Spricigo, D.A.; Bardina, C.; Llagostera, M. Remarkable diversity of Salmonella bacteriophages in swine and poultry. FEMS Microbiol. Lett. 2015, 362, 1-7. [CrossRef]

24. O'Neil, J. Antimicrobial Resistance: Tackling a Crisis for the Health and Wealth of Nations; HM Government: London, UK, 2014.

25. De Kraker, M.E.A.; Stewardson, A.J.; Harbarth, S. Will 10 million people die a year due to antimicrobial resistance by 2050? PLoS Med. 2016, 13, 1002184. [CrossRef]

26. More, S.J. European perspectives on efforts to reduce antimicrobial usage in food animal production. Ir. Vet. J. 2020, 73, 2. [CrossRef]

27. Roth, N.; Käsbohrer, A.; Mayrhofer, S.; Zitz, U.; Hofacre, C.; Domig, K.J. The application of antibiotics in broiler production and the resulting antibiotic resistance in Escherichia coli: A global overview. Poult. Sci. 2019, 98, 1791-1804. [CrossRef] [PubMed]

28. Ljubojevic, D.; Pelic, M.; Puvača, N.; Milanov, D. Resistance to tetracycline in Escherichia coli isolates from poultry meat: Epidemiology, policy and perspective. Worlds Poult. Sci. J. 2017, 73, 409-417. [CrossRef]

29. Davies, J.; Davies, D. Origins and evolution of antibiotic resistance. Microbiol. Mol. Biol. Rev. 2010, 74, 1092-2172. [CrossRef] [PubMed]

30. Bao, H.; Zhang, H.; Wang, R. Isolation and characterization of bacteriophages of Salmonella enterica serovar Pullorum. Poult. Sci. 2011, 90, 2370-2377. [CrossRef] [PubMed]

31. Hungaro, H.M.; Mendonça, R.C.S.; Gouvêa, D.M.; Vanetti, M.C.D.; de Pinto, C.L.O. Use of bacteriophages to reduce Salmonella in chicken skin in comparison with chemical agents. Food Res. Int. 2013, 52, 75-81. [CrossRef]

32. Wei, S.; Chelliah, R.; Rubab, M.; Oh, D.H.; Uddin, M.J.; Ahn, J. Bacteriophages as potential tools for detection and control of Salmonella spp. In food systems. Microorganisms 2019, 7, 570. [CrossRef]

33. Commission Regulation. No 2160/2003 of the European Parliament and of the Council as Regards Requirements for the Use of Specific Control Methods in the Framwork of the National Programmes for the Control of Salmonella in Poultry. Available online: https:/eur-lex.europa.eu/LexUriServ/LexUriServ.do?uri=OJ:L:2006:212:0003:0005:EN:PDF (accessed on 4 June 2020).

34. EFSA and ECDC. The use of vaccines for the control of Salmonella in poultry Opinion of the Scientific Panel on Biological Hazards on the requests from the Commission related to the use of vaccines for the control of Salmonella in poultry. EFSA J. 2004, 114, 1-74.

35. Greenwood, B. The contribution of vaccination to global health: Past, present and future. Philos. Trans. R. Soc. B Biol. Sci. 2014, 369, 20130433. [CrossRef] 
36. Lee, H.Y.; Biswas, D.; Ahn, J. In-vitro adhesion and invasion properties of Salmonella Typhimurium competing with bacteriophage in epithelial cells and chicken macrophages. Rev. Bras. Cienc. Avic. 2015, 17, 427-432. [CrossRef]

37. Kilroy, S.; Raspoet, R.; Devloo, R.; Haesebrouck, F.; Ducatelle, R.; Immerseel, F. Oral administration of the Salmonella Typhimurium vaccine strain Nal2/Rif9/Rtt to laying hens at day of hatch reduces shedding and caecal colonization of Salmonella 4,12:i:-, the monophasic variant of Salmonella Typhimurium-ScienceDirect. Inmunol. Heal. Dis. 2015, 94, 1122-1127. [CrossRef]

38. Petsong, K.; Benjakul, S.; Chaturongakul, S.; Switt, A.I.M.; Vongkamjan, K. Lysis profiles of Salmonella phages on Salmonella isolates from various sources and efficiency of a phage cocktail against $\mathrm{S}$. Enteritidis and S. Typhimurium. Microorganisms 2019, 7, 100. [CrossRef]

39. Hagens, S.; Loessner, M.J. Application of bacteriophages for detection and control of foodborne pathogens. Appl. Microbiol. Biotechnol. 2007, 76, 513-519. [CrossRef] [PubMed]

40. Marin, C.; Lainez, M. Salmonella detection in feces during broiler rearing and after live transport to the slaughterhouse. Poult. Sci. 2009, 88, 1999-2005. [CrossRef] [PubMed]

41. EFSA and ECDC. The Community Summary Report on Trends and Sources of Zoonoses, Zoonotic Agents, Antimicrobial Resistance and Foodborne Outbreaks in the European Union in 2006. EFSA J 2007, 130, $2-352$.

(C) 2020 by the authors. Licensee MDPI, Basel, Switzerland. This article is an open access article distributed under the terms and conditions of the Creative Commons Attribution (CC BY) license (http://creativecommons.org/licenses/by/4.0/). 